\title{
Democracia Cosmopolita e as Armas Nucleares
}

\author{
Martonio Mont Alverne Barreto Lima \\ Graduado em Direito pela Universidade de Forta- \\ leza (1988), mestre em Direito (Direito e Desen- \\ volvimento) pela Universidade Federal do Ceará \\ (1993). Doutor em Direito (Rechtswissenschaft) \\ pela Johann Wolfgang Goethe-Universität Frank- \\ furt am Main (1998), sob a orientação do prof. \\ dr. Wolf Paul. Pós-doutor em Direito pela mesma \\ Universidade de Frankfurt/M. Professor titular do \\ Programa de Pós-Graduação em Direito (PPGD) da \\ Universidade de Fortaleza e Procurador do Municí- \\ pio de Fortaleza.barreto@unifor.br
}

\section{Mariana Luz Zonari}

Graduada em Direito pela Universidade de Fortaleza (Unifor). Advogada. Pós-graduada em Direito Empresarial e mestre em Direito Constitucional pela Universidade de Fortaleza (Unifor). Pesquisadora do CNPQ no grupo de pesquisa intitulado "Energia Nuclear - Aspectos Legais e Geopolítica da Atualidade". Autora do livro "O Tratado de Não Proliferação de Armas Nucleares: Desafios para a Democracia entre as Nações". marilzonari@gmail. com.

\section{Resumo}

Desde a publicação de À Paz Perpétua, de Kant, em 1795, a influência da tese de que o regime democrático, no qual os cidadãos tivessem livre poder de decisão sobre a guerra, seria a única alternativa para a obtenção da paz mundial, bem como os posteriores e renomados estudos de David Held, Robert Dahl e Danilo Zollo sobre a intrínseca relação entre democracia e política internacional, têm 
feito ressurgir nos últimos anos as pesquisas sobre a questão do impacto da globalização nas instituições democráticas contemporâneas. Partindo dessa premissa e, também, sabendo-se dos efeitos que o processo de globalização tem demonstrado ter sobre os institutos democráticos existentes atualmente e, consequentemente, sobre os conceitos westfalianos de Estado-Nação, autonomia e soberania estatal, a presente pesquisa busca retomar o debate sobre um assunto de demasiada importância tanto para a teoria da democracia quanto para a segurança internacional: 0 tema da participação democrática dos cidadãos nos processos decisórios de assuntos complexos como a questão nuclear.

Palavras-chave: Democracia. Sistema internacional. Cosmopolitismo. Armas nucleares.

\title{
Cosmopolitan Democracy and Nuclear Weapons
}

\begin{abstract}
Since the publication of Kant's Perpetual Peace in 1795, the influence of the thesis that the democracy, through which the citizens would have free power to decide on matters of war, would be the only alternative for obtaining world peace, as well as post and renowned studies of David Held, Robert Dahl and Danilo Zollo on the intrinsic relationship between democracy and international politics, have made resurge in recent years researches on the question of the impact of globalization on contemporary democratic institutions. From this premise and, also, knowing the effects that the globalization process has been shown to have on today's existing democratic institutions, and consequently on the Westphalian concepts of nation-state, autonomy and state sovereignty, this research seeks to resume debate on a subject of substantial importance for the theory of democracy and to international security: the issue of democratic participation of citizens in the decision-making of complex issues such as the nuclear question.
\end{abstract}

Keywords: Democracy. International system. Cosmopolitanism. Nuclear weapons.

Recebido em: 19/3/2017

Revisões requeridas em: 20/5/2017

Aceito em: 30/5/2017

\section{Sumário}

1 Introdução. 2 Cosmopolitismo e Democracia Global. 3 A Democracia Cosmopolita e as Armas Nucleares. 4 Conclusões. 5 Referências. 


\section{INTRODUÇÃO}

A democracia é um tema tão estudado quanto divergente. Muitas têm sido as pesquisas sobre o assunto, tanto no sentido de analisar os seus aspectos positivos quanto para apontar críticas a alguns objetivos propostos e aparentemente não atingidos pelos regimes democráticos.

Recentemente, contudo, um tópico específico parece ter retomado a atenção dos estudiosos: a questão da democratização do sistema internacional. Esse retorno do debate cosmopolita, do deslocamento do locus da democracia do Estado-Nação para o âmbito global, parece ter sido influenciado pela ideia de lei cosmopolita kantiana trazida a público pela $\grave{A} \mathrm{Paz}$ Perpétua em 1795 (KANT, 2015) e reforçado recentemente pelo relativamente novo conceito de democracia cosmopolita de David Held (1995).

O amplo processo de globalização em que estamos inseridos atualmente, no qual há uma verdadeira e profunda integração econômica, política, social e cultural entre os países, em que fatores internos e externos se confundem e transcendem as fronteiras nacionais, evidencia sérias consequências ao conceito de Estado-Nação como principal forma de organização política e, em decorrência, às bases da democracia como forma de governo.

Esse processo de globalização sugere, pelo menos ao que parece, que a ampliação do cenário político, passando do âmbito nacional para o internacional, não está sendo devidamente acompanhado pela correspondente ampliação dos mecanismos democráticos (REIS, 2006). Dessa forma, passa-se a questionar tanto a legitimidade da democracia contemporânea como a própria autonomia dos Estados e, também, o modelo westfaliano de soberania.

Segundo Held (1991, p. 146), vive-se um verdadeiro paradoxo: ao mesmo tempo em que a democracia passa a ganhar força como forma de governo ideal, passa-se a questionar a eficácia dos meios democráti- 
cos dentro do cenário global. "As nações proclamam-se democráticas no momento em que mudanças no âmbito da ordem internacional comprometem a possibilidade de um Estado-nação democrático independente” (1991, p. 146).

Percebe-se, dessa forma, que o surgimento da globalização apenas acentuou alguns problemas que a democracia representativa já enfrentava anos antes, tal como a distância entre os cidadãos e as tomadas de decisão, quase sempre elitistas. $\mathrm{O}$ próprio cenário mundial atual revela um alto nível de insatisfação com os mecanismos democráticos contemporâneos, que isolam os processos decisórios, mantendo-os cada vez mais distantes daqueles que efetivamente deveriam participar das decisões políticas relevantes: os cidadãos.

Diante desse processo de crescente interdependência entre a democracia e as relações internacionais, muitos temas ultrapassam as fronteiras nacionais e passam a exigir um debate mundial, uma vez que as decisões tomadas por um Estado-Nação agora afetam - pelo menos potencialmente - indivíduos que estão fora deste Estado e, por consequência, não fizeram parte do processo decisório sobre aquele tema (HELD, 1991, p. 151).

Um dos mais importantes assuntos de segurança que ultrapassa as fronteiras nacionais e é vital para toda a humidade é o desenvolvimento e a utilização das armas nucleares. Dahl, explicitando sua tese de que em problemas complexos como o das armas atômicas os cidadãos encontram-se excluídos dos debates e, consequentemente, das decisões finais, afirma:

Perhaps no public question poses the challenge of guardianship more starkly than American policies concerning nuclear weapons. Nuclear weapons present a tragic paradox: No decisions can be more fateful for 
Americans, and for the world, than decisions about nuclear weapons. Yet these decisions have largely escaped the control of the democratic process (DAHL, 1985, p. 3). ${ }^{1}$

Dessa forma, a presente pesquisa se mostra não só relevante, mas atual. A existência das armas nucleares, somada ao problema relativo à sua dualidade de usos, que não somente dificulta, mas, de certa forma, até mesmo impossibilita a separação do seu uso pacífico e bélico-militar, impõe um grande desafio à segurança internacional moderna.

A grande questão para a qual se busca resposta neste artigo - ou, pelo menos de uma maneira mais modesta, a ampliação do debate - é a seguinte: As instituições da democracia contemporânea, já amplamente afetadas pelo déficit democrático da moderna ordem global, são adequadas para lidar satisfatoriamente com os problemas complexos, especialmente a questão nuclear?

Metodologicamente, a pesquisa utilizada foi bibliográfica, mediante análises, comparações e conclusões embasadas em trabalhos publicados sob a forma de livros, revistas, artigos e publicações especializadas, que abordam direta ou indiretamente o tema em estudo. No que tange à tipologia - utilização dos resultados - a presente pesquisa é pura, tendo como finalidade o aumento do conhecimento dos pesquisadores, objetivando uma nova tomada de posição. A abordagem é qualitativa, de caráter exploratório e descritiva quanto aos objetivos.

Assim, o presente trabalho está dividido em três grandes partes: a primeira, na qual será abordada a questão do cosmopolitismo e da democracia global, fazendo-se um elo entre os conceitos de democracia e a pro-

1 Talvez nenhuma questão pública coloque o desafio do guardianship mais claro do que as políticas americanas em matéria de armas nucleares. As armas nucleares apresentam um paradoxo trágico: nenhuma decisão pode ser mais fatal para os americanos e para o mundo do que as decisões sobre armas nucleares. Ainda assim, tais decisões têm amplamente escapado do controle do processo democrático (Tradução nossa). 
blemática da sua inserção no âmbito do sistema internacional; a segunda parte, quando será analisado o assunto das armas nucleares no âmbito internacional e da democracia global e, por fim, as conclusões.

\section{COSMOPOLITISMO E DEMOCRACIA GLOBAL}

A democracia tem enfrentado toda sorte de obstáculos no século 20. Talvez num dos períodos em que mais se esperava da democracia, foi quando mais ela falhou. Como nada existe no abstrato, não se pode cobrar esta conta da ideia de democracia, mas dos atores políticos que dela se enamoraram e prometeram o que não cumpriram... e estavam cônscios de que não poderiam cumprir. Para Robert Dahl (1994), é possível distinguir três momentos históricos em que, notoriamente, é viável perceber as modificações da democracia política.

O primeiro desses momentos é a conjuntura de surgimento do sistema democrático, na primeira metade do século $5^{\circ}$ a.C. na Grécia, onde as Cidades-Estados gregas passaram de sistemas não democráticos para a democracia direta. $\mathrm{O}$ segundo grande momento de transformação da democracia ocorre com o surgimento dos Estados nacionais e, consequentemente, das democracias nacionais, as quais, por suas grandes dimensões territoriais, exigiam não mais uma democracia direta, mas sim a representação.

É nesse contexto da democracia representativa que surge o problema do distanciamento entre os reais interesses dos cidadãos - os quais paradoxalmente são diretamente afetados pelas decisões estatais - e o que efetivamente é decidido por aqueles que têm o poder para tanto. $\mathrm{Ou}$ seja, perdura na democracia contemporânea uma disparidade entre a (in) capacidade dos cidadãos de demandar certas tomadas de decisão do poder público e a habilidade de uma efetiva resposta por parte do Estado democrático representativo (BOBBIO, 1988). 
De acordo com Rafael Villa e Ana Paula Tostes (2006), citando Dahl (1994), o momento atual marca a terceira grande transformação das dimensões democráticas: a era da transnacionalidade da política. Diante dos efeitos do processo que se convencionou chamar de globalização, os Estados, atores clássicos do sistema internacional, passaram a perder as condições necessárias ao controle da sua autonomia política, o que vem minando alguns dos fundamentos basilares da ordem de Westfália, ${ }^{2}$ fundada nos conceitos de soberania e autonomia e tendo como principal pressuposto a territorialidade.

A efetividade do sistema de governabilidade global fundado em 1648 vem sendo paulatinamente enfraquecida pelo surgimento de novas forças e atores transnacionais influentes, desgastando a base de poder nacional tradicional e corroendo o princípio do direito do mais forte no âmbito internacional e a afirmação da soberania estatal absoluta (HAYDEN, 2004).

Referido processo de interdependência econômica, territorial e geopolítica passou a redefinir os conceitos de cidadania e democracia, os quais passaram do âmbito exclusivamente territorial para o critério global,

\footnotetext{
2 Segundo McGrew (1998), "os princípios da ordem de Westphalia, tais como se têm desenvolvido nos últimos três séculos, são quatro: i) territorialidade, que é o princípio central da organização política moderna, já que sempre houve a necessidade da existência de fronteiras territoriais para a definição de limites de jurisdição legal e a consequente demarcação da extensão da autoridade coercitiva; ii) soberania, como sendo a última fonte de autoridade política e legal sobre o povo dentro de um território determinado e para fora dele; iii) autonomia, princípio que atribui, única e exclusivamente, ao Estado a capacidade de conduzir suas relações políticas externas e internas. Desse modo, só aos Estados compete a decisão sobre a concessão de poder ou a subjugação a uma autoridade externa; iv) e, por fim, a legalidade, que significa que as relações entre Estados soberanos podem estar sujeitas a leis internacionais, apenas na medida em que cada Estado consinta em ser compelido. Não podendo haver, portanto, autoridade legal acima do Estado que possa impor obrigações legais sobre ele ou sobre os cidadãos" (TOSTES; VILLA, 2006, p. 92).
} 
comprometendo fundamentalmente a figura do Estado-Nação, conforme fundado em Westfália, e, consequentemente, a noção de soberania - estabelecida sobre a ideia de supremacia legal territorial.

Percebe-se que as concepções de autonomia, soberania e cidadania se encontram diretamente ligadas e são, juntamente com a democracia representativa, amplamente afetadas pelo processo hegemônico de globalização. De acordo com David Held (1991, p. 22):

As fronteiras nacionais tradicionalmente demarcaram as bases nas quais os indivíduos eram incluídos ou excluídos da participação nas decisões que afetam suas vidas; mas se muitos processos socioeconômicos e os resultados das decisões sobre esses processos se estendem para além das fronteiras nacionais, então as implicações desse fenômeno são sérias, não apenas para as categorias de legitimidade e consenso, mas para todas as ideias-chave da democracia.

Do mesmo modo e alinhados às concepções de Held, pensam diversos outros estudiosos sobre o tema, tais como Bobbio (1992) e Dahl (1982), para quem as “[...] mudanças na escala da vida política podem (mais uma vez) alterar os limites e as possibilidades do processo democrático” (DAHL, 1982, p. 312). Também nessa mesma linha de pensamento, afirma McGrew (1998, p. 55):

Se a soberania estatal, em vez de ilimitada, passar a ser mais compartilhada com agências internacionais; se os estados tiverem cada vez menos controle sobre seus próprios territórios; e se as fronteiras políticas e territoriais forem crescentemente permeáveis, o núcleo de princípios da democracia liberal - autogoverno, consentimento, representação e soberania popular - torna-se inequivocadamente problemático.

Dessa maneira, tornam-se visíveis as sequelas resultantes do processo de globalização na democracia política e na cidadania democrática de base territorialista, tornando cada vez mais frágeis os pressupostos 
básicos da teoria da democracia liberal, conforme pensada em Westfália, e evidenciando um verdadeiro abismo entre os ideais democráticos e os da globalização liberal (RODRIGUES, 2004, p. 94).

O déficit democrático da governança global traz sérias consequências para o desenvolvimento econômico, uma vez que o elitismo do processo decisório gera o aumento da pobreza e da desigualdade (HAYDEN, 2004). Conforme observa Archibugi (2003, p. 9): "Esse é o verdadeiro déficit da democracia: a existência de interesses transnacionais organizados distante de qualquer mandato popular”.

Diante de tais constatações, há estudiosos que consideram que, pelo menos do ponto de vista democrático, a globalização e a internacionalização das relações políticas são processos negativos. Para exemplificar, pode-se citar o ensaio do diplomata francês Jean Guéhenno (1994), no qual ele defende a tese de que o amplo processo de globalização, que mitiga a importância territorial, enfraquece a democracia. De outro lado, existem os que acreditam que a única forma de sobrevivência da democracia diante da globalização é a sua expansão - senão, mudança - para o âmbito transnacional (REIS, 2006).

De uma forma ou de outra, tais divergências remontam a três debates clássicos do pensamento político: o problema do locus da democracia, as disputas entre o realismo e o idealismo e, também, a controvérsia entre os comunitaristas e os cosmopolitas. De acordo com Reis (2006, p. 18), "Posto de uma forma simples, se trata de investigar se a cidadania e a democracia são ou não instituições inerentemente vinculadas a um espaço político fechado, como o Estado nacional”.

Immanuel Kant, em um dos seus trabalhos mais celebrados e renomados, À Paz Perpétua (2015), dedicou-se a combater a ênfase do realismo no chamado estado natural internacional, caracterizado pelo poder e pelo conflito, propondo, em oposição, “[...] um sistema de justiça internacional fundado em princípios fortes da lei cosmopolita e internacional, dese- 
nhado para restringir os poderes dos Estados - mas não a sua liberdade -, de maneira análoga à ordem normativa da constituição republicana” (HAYDEN, 2004, p. 87).

Em À Paz Perpétua, centro do seu pensamento cosmopolita, político e moral, Kant propõe a criação de uma federação mundial de Estados livres, partindo da premissa de que, para que estes Estados assim o fossem, seria necessário que adotassem a forma republicana. Importante ressaltar que tal federação mundial jamais deve ser confundida - como comumente acontece - com a formação de um Estado mundial. Pelo contrário, o cosmopolitismo não é contrário à existência dos Estados ou, ainda, ao conceito westfaliano de Estado-nação (KANT, 2015).

O filósofo sugere que todos os homens deveriam ser considerados pela sua condição de membros da humanidade e, dessa forma, capazes de tomar suas decisões políticas pessoais. Para Kant, a ideia do direito cosmopolita é a única capaz de garantir não somente a autonomia dos indivíduos, mas também a paz mundial pois, segundo o autor, somente em um regime em que os cidadãos tivessem o poder de decidir sobre a guerra haveria a paz (KANT, 2015).

A consolidação de um direito cosmopolita fundado na hospitalidade emerge como artigo definitivo da paz, uma vez que a chegada de estrangeiros em outros Estados somente será pacífica se garantida pela lei universal da hospitalidade. Os atuais conflitos étnicos desencadeadores das mais significativas guerras exibiu ao mundo, novamente, que, apenas argumentativamente, se a paz eterna como proposta por Kant não passa de idealismo, não deixa de serem estas ponderações produto da mais arguta observação diante da realidade que se tinha. De uma construção tão decididamente baseada em acontecimentos reais não há como deixar de reconhecer na sua parte propositiva algum realismo, ou melhor, uma totalidade realisticamente concatenada. 
Concebidos desta maneira, os artigos preliminares e definitivos da paz eterna articulam-se entre si a partir de uma observação histórica concreta de seu autor e o contexto de sua vida. Os artigos formuladores da paz kantiana em nada significam idealismo e sua necessidade na política externa da atualidade parece confirmar o seu realismo pela razão de que a previsão é de que as nações resolvam seus conflitos segundo o Direito Internacional, por elas próprias estabelecido - uma vez que são repúblicas democráticas - e num foro internacional pelos diferentes países fundado e mantido. Concebida desta maneira e comparada com os desafios da atualidade, a visão de uma paz eterna abandona o terreno do impossível, dado que nada de seus parâmetros de fundação requer a transformação radical dos homens em outro tipo de homem. A paz eterna como pensada por Kant é aplicável aos homens que vivem na Terra e nela querem permanecer.

Nesse sentido, também, é o pensamento do filósofo alemão Jürgen Habermas, para o qual é necessário que os indivíduos se reconheçam não somente como membros de comunidades particulares, mas, além disso, como membros da humanidade, cidadãos do mundo. Faz-se imprescindível que sejam criados canais de participação democrática mais eficientes e que permitam a interferência dos cidadãos no plano transnacional, o que só será efetivo com a transformação da consciência dos indivíduos (HABERMAS, 2001).

Inspirado no pensamento filosófico kantiano de bases estoicas, que, no pensamento de Hayden (2004), é a tentativa ideológica mais completa de aplicação do modo moderno do pensamento cosmopolita às questões políticas, surge então nos últimos anos o conceito de democracia cosmopolita, que tem em David Held (1995) um de seus maiores expoentes. Tal 
conceito parte das três premissas básicas do cosmopolitismo moderno ${ }^{3}$ para criar um modelo de democracia que - espera-se - seja capaz de solucionar as deficiências da governança global, especialmente o déficit de legitimidade democrático.

O projeto da democracia cosmopolita, conforme pensado por David Held (1995), demonstra ser uma tentativa de conectar a teoria cosmopolita kantiana com a construção de instituições modernas cosmopolitas, capazes de assegurar a democracia no âmbito global e garantir a consolidação da autonomia individual. Busca também a retomada da ideia de cidadania em um mundo globalizado e o fim da hierarquia de poder existente no cenário internacional entre os Estados mais ricos e poderosos em detrimento dos demais. Corroborando com Held, Archibugi (2003, p. 8) afirma:

Acima de tudo, o que diferencia a democracia cosmopolita de outros projetos é a sua tentativa de criar instituições que permitam a voz dos indivíduos de ser ouvida em assuntos globais, independentemente de sua repercussão em casa. A democracia como uma forma de governança global, portanto, precisa ser realizada em três níveis diferentes e interconectados: nos Estados, entre Estados e em nível mundial.

Percebe-se que o modelo de democracia proposto por Held é um projeto normativo abrangente, que visa a minimizar as falhas democráticas do Estado-Nação diante da globalização, propondo o deslocamento do locus da democracia para a esfera internacional.

3 De acordo com Hayden (2004, p. 84), "O cosmopolitismo, em sua forma moderna, é a articulação sistemática de três premissas básicas. A primeira é que seres humanos, como indivíduos, representam as unidades fundamentais da preocupação moral e política. [...] A segunda premissa, cuja articulação teórica moderna é conhecida como universalismo, significa que todos os seres humanos possuem um status moral igual. [...] Todas as pessoas em todos os lugares têm o mesmo direito ao status humano. Por fim, a terceira premissa diz respeito aos indivíduos como objetos de preocupação de todos, isto é, o status humano ocupa um âmbito global. Em outras palavras, ninguém pode se isentar de suas obrigações de respeitar o status moral igual de todos os outros seres humanos.” 
Todo esse modelo de democracia cosmopolita é baseado no princípio da autonomia, que se resume na tese defendida por Held de que a globalização foi responsável pelo crescimento de situações de tomadas de decisão em âmbito nacional que afetam o âmbito global, sem, contudo, que os Estados ou os indivíduos afetados tenham participação ou influência sobre tais decisões. Percebe-se, dessa forma, que, na visão de Held, todos os indivíduos têm capacidade para participar das decisões políticas que venham a ter impacto direto sobre eles (HELD, 1995).

\section{A DEMOCRACIA COSMOPOLITA E AS ARMAS NUCLEARES}

É nesse ponto que se insere o debate sobre as armas nucleares. De uma maneira geral, acredita-se que o direito dos indivíduos como pessoas igualmente capazes e dotadas de moralidade de participar nas tomadas de decisão políticas relevantes e com consequências importantes sobre os seus interesses individuais e coletivos é o que justifica o processo democrático.

Dessa forma, a questão nuclear, especialmente por seu aspecto literalmente vital, demonstra ser um assunto de demasiada importância e do qual decorrem sérias consequências para os cidadãos. Se adotarmos como premissa o fato de que as decisões relacionadas às armas nucleares têm sido tomadas, desde a sua descoberta, por um pequeno e seleto grupo de pessoas, quase sempre em segredo absoluto e em um escopo completamente externo e distante dos controles democráticos, então teremos de admitir que existe uma profunda falha nas instituições democráticas hoje existentes em atingir os seus propósitos (DAHL, 1985). 
Permitir que um pequeno grupo de pessoas, extremamente distantes das vontades dos cidadãos, tomem as suas decisões é ir de encontro ao Strong Principle of Equality e em direção ao Principle of Guardianship, também chamado de Principle of Meritocratic Rulership. Dahl (1985, p. 6), explicando o conflito entre esses dois princípios, argumenta:

[...] taken all around, adults are adequately qualified to participate in making the collective decisions that they will be required to obey, as with laws, and that no minority among them is so clearly better qualified that its members are entitled to make all collective decisions. This assumption does not exclude the possibility that people may choose to delegate some collective decisions to others whom they think to be better qualified in the particular instance. It does imply that the citizens are qualified to judge which questions require delegation, to set the terms on which the delegation is to take place, and to recapture the delegated authority when they choose. In short, the assumption allows for delegation of authority but not its alienation. Let me call this assumption the Strong Principle of Equality. The alternative assumption is that generally speaking most adults are not qualified to make binding collective decisions, whereas a minority among them is well qualified to do so, or at least in some conditions could be. Drawing on Plato's term for his rulers in The Republic, we might call this assumption the Principle of Guardianship, or if one prefers a word of recent coinage, the Principle of Meritocratic Rulership. ${ }^{4}$

4 [...] genericamente, os adultos são devidamente qualificados a participar nas tomadas de decisão coletivas que eles serão obrigados a obedecer, como com as leis, e que nenhuma minoria entre eles é tão nitidamente mais qualificada que os seus membros têm o direito de tomar todas as decisões coletivas pelos demais. Esta hipótese não exclui a possibilidade de que as pessoas podem optar por delegar algumas decisões coletivas para outros a quem eles acham que seriam mais bem qualificados no caso particular. Ela implica que os cidadãos estão qualificados a julgar que perguntas exigem delegação, para definir as condições em que a delegação terá lugar, e para recapturar a autoridade delegada quando assim optarem. Em suma, a hipótese permite a delegação de autoridade, mas não a sua alienação. Deixe-me chamar essa suposição de Princípio da Igualdade forte. A suposição alternativa é de que de um modo geral a maioria dos adultos não estão qualificados para tomar decisões coletivas vinculantes, enquanto uma minoria entre eles é bem qualificada para fazê-lo, ou pelo menos em algumas condições poderia ser. Baseando-se em termo de 
Dahl (1985) observa que os atuais regimes democráticos comumente recorrem a um sistema político misto, no qual ora o Strong Principle of Equality é adotado, ora se abre espaço para o Principle of Guardianship. No que diz respeito às armas nucleares, contudo, nós, de fato, não delegamos, mas sim transferimos para um pequeno grupo de pessoas - supostamente mais qualificadas - o poder de decisão sobre um assunto de importância incalculável para a vida humana. Para o autor - visão com a qual corroboramos, quando o assunto é armas nucleares - nós vivemos em uma democracia baseada no Guardianship e não no Principle of Equality (DAHL, 1985).

A visão de Dahl (1985), de que as decisões sobre assuntos globais e de extrema importância como as armas nucleares não podem ser excluídas do amplo processo democrático, se coaduna com a de David Held (1995), segundo a qual a construção de uma ordem cosmopolita, por meio da qual houvesse efetiva participação dos cidadãos em assuntos fora das fronteiras dos seus Estados-Nação, é a única solução para o desafio imposto à democracia pelo processo de globalização.

Apresentando uma visão ainda mais radical sobre o assunto, Wellen (2013), endossando o pensamento de Elaine Scarry (2014) apresentado em seu trabalho seminal Thermonuclear Democracy: Choosing between Democracy and Doom, afirma: "The case can be made that nuclear weapons are the ultimate test of democracy. But the stakes are too high if we lose. In fact, the existence of nuclear weapons needs to adjust to the needs of society by eliminating them" (WELLEN, 2013).

Platão para seus governantes em A República, poderíamos chamar essa suposição o Princípio da tutela, ou se se prefere uma palavra de cunhagem recente, o Princípio da Regência da Meritocrática (Tradução nossa).

5 Pode-se argumentar que as armas nucleares são o teste final da democracia, mas as apostas são muito altas se perdermos. De fato, a existência de armas nucleares precisa se ajustar às necessidades da sociedade eliminando-as (Tradução Nossa). 
Diante dos desafios impostos pela descoberta da energia atômica, sendo o principal deles a característica da dualidade de usos dos materiais e tecnologias associados à energia nuclear, o que gera a enorme dificuldade - senão impossibilidade - de separação do uso pacífico deste tipo de energia do seu emprego bélico-militar, e, partindo-se da premissa de que o único tratado internacional que versa sobre o tema - o Tratado de Não Proliferação de Armas Nucleares - apesar de ser relativamente bem-sucedido no que respeita à adesão, tendo regime quase universal, não possuindo abrangência mundial apenas pela recusa de Israel, Índia e Paquistão em aderirem ao tratado e pela retirada, em 2003, da Coréia do Norte, tem enfrentado inúmeros desafios que prejudicam a sua continuidade, resta-nos filiarmo-nos ao posicionamento de Elaine Scarry (2014) e Wellen (2013), no sentido de defender a completa eliminação dos armamentos atômicos.

A verdade por trás da questão nuclear é que, nos últimos 70 anos desde a sua invenção secreta durante a Segunda Guerra Mundial, não houve qualquer discussão pública e efetivamente democrática sobre o seu uso e as informações e dados sobre o assunto são - praticamente todos secretos, o que revela a tendência mundial atual de optar pelos sistemas democráticos baseados no Guardianship e na exclusão da participação dos cidadãos nas tomadas de decisão envolvendo assuntos complexos como a questão nuclear.

\section{CONCLUSÕES}

A presente pesquisa foi norteada pela busca de resposta à seguinte indagação: Afinal, as instituições da democracia contemporânea, já amplamente afetadas pelo déficit democrático da ordem moderna global, são adequadas para lidar satisfatoriamente com os problemas complexos, especialmente a questão nuclear? Parece-nos que não. 
Demonstrou-se que a democracia sofreu diversas transformações, passando do modelo direto para a representatividade, a qual, pelo menos até então e apesar de diversos desafios enfrentados, era considerada razoavelmente satisfatória.

O surgimento de um conjunto de transformações na ordem política e econômica mundial desde o final do século 20 que tornou o mundo interconectado - processo que se convencionou chamar de globalização - tem feito com que os cidadãos percam, paulatinamente, o controle sobre as ações políticas estatais. Isso ocorre por que, em um mundo internacionalmente interligado, decisões importantes são comumente tomadas sem a mínima participação daqueles que, efetivamente, vão ser afetados por elas.

É por essa razão que os estudos sobre a questão da democratização do sistema internacional têm ganhado força novamente. $\mathrm{O}$ amplo processo de globalização no qual estamos inseridos torna quase que inexistentes as fronteiras nacionais, trazendo sérias consequências para o conceito de Estado-Nação de base territorial e para as concepções liberais de cidadania, soberania e autonomia, conforme estipuladas na ordem westfaliana, comprometendo-as.

São perceptíveis as consequências resultantes do processo de globalização hegemônica na democracia política e na cidadania democrática de base territorialista, tornando cada vez mais frágeis os pressupostos básicos da teoria da democracia liberal e realçando a enorme disparidade existente entre a ideologia liberal contemporânea e o processo capitalista de globalização.

Buscando superar as sequelas trazidas pela globalização, responsáveis pelo surgimento do chamado déficit de legitimidade democrático da governança global e com base no fato de que existem, atualmente, diversos interesses transnacionais que são decididos distantes de qualquer mandato popular, David Held apresenta o que chama de projeto da democracia cosmopolita. 
Por meio desse projeto, Held e os demais defensores da democracia global, inspirados no pensamento filosófico kantiano de bases estoicas, propõem uma concepção normativa abrangente, que visa a minimizar as falhas democráticas do Estado-Nação diante da globalização, sugerindo a expansão do locus da democracia do âmbito nacional para a esfera internacional.

Tendo como base o princípio da autonomia, o grande objetivo da democracia cosmopolita proposta nos modelos de Held é assegurar um debate mundial sobre os assuntos relevantes e a efetiva participação dos cidadãos no processo decisório desses assuntos, o que, de fato, não ocorre nas instituições democráticas representativas da atualidade.

Nesse âmbito, defendeu-se que, apesar de ser dos mais importantes assuntos de segurança internacional e que, portanto, ultrapassa as fronteiras dos Estados-Nação, a política nuclear é restrita a um pequeno e restrito grupo de pessoas, consideradas, nos moldes de Platão em a República, como as mais capacitadas para as tomadas de decisão nesse assunto.

Percebe-se que, se adotarmos como premissa o fato de que as decisões relacionadas às armas nucleares têm sido tomadas, desde a sua descoberta, por um pequeno e seleto grupo de pessoas, quase sempre em segredo absoluto e em um escopo completamente externo e distante dos controles democráticos, então teremos de admitir que existe uma profunda falha nas instituições democráticas hoje existentes em atingir os seus propósitos democráticos.

\section{REFERÊNCIAS}

ALBUQUERQUE, Newton de Menezes; FABRÍCIO, Paulo Eduardo Magnani. A democracia no sistema internacional. Revista Pensar, Fortaleza, v. 17, n. 1, p. 297-317, jan./jun. 2012. 
ARCHIBUGI, D. Cosmopolitical democracy. Debating Cosmopolitics. Londres: Verso, 2003.

BOBBIO, Norberto. Liberalismo e democracia. São Paulo: Brasiliense, 1988. . O futuro da democracia. São Paulo: Paz e Terra, 1986. . A era dos direitos. 11. ed. Rio de Janeiro: Campus, 1992.

BORN, Hans. National governance of nuclear weapons: oportunities and constraints. Geneva: Geneva Centre for the Democratic Control of Armed Forces (DCAF); Sipri Yearbook (Armaments, disarmaments and international security), 2006.

CHAIA, Vera Lúcia. Globalização e democracia. Revista Mediações, Londrina, Edição Especial, p. 7-17, 1997.

DAHL, Robert. Controlling nuclear weapons: democracy versus guardianship. Syracuse (NY): Syracuse University Press, 1985.

. The concept of power. Behavioral Science. Department of political science of Yale University, july 1957.

. A democratic dilemma: system effectiveness versus citizen participation. Political Science Quartely, v. 109, n. 1, p. 23-34, 1994.

. Dilemmas of pluralista democracy: autonomy vs. Control. New Heaven: Yale University Press, 1982.

GUÉHENNO, Jean, M. O fim da democracia: um ensaio profundo e visionário sobre o próximo milênio. Rio de Janeiro: Bertrand Brasil, 1994.

HABERMAS, J. A constelação pós-nacional: ensaios políticos. São Paulo: Littera Mundi, 2001.

HAYDEN, Patrick. Kant, Held and the imperatives of cosmopolitan politics. Tradução Nuno Coimbra Mesquita (USP). Revista de Ciências Sociais e Humanas da Universidade Metodista de Piracicaba, São Paulo, v. 15, n. 38, p. 83-94, 2004. 
HELD, David. A democracia, o Estado-Nação e o sistema global. Tradução Régis de Castro Andrade. Trabalho apresentado na Conferência "Aprofundando e globalizando a democracia” realizada em Yokohama, Japão, 17-22 de março de 1990. Revista de Cultura e Política Lua Nova, São Paulo, v. 23, p. 146-194, 1991.

. Democracy and the global order. from the modern state to cosmopolitan governance. California: Stanford University Press, 1995.

KANT, Immanuel. À Paz Perpétua. Tradução Marco Zingano. Porto Alegre: L\&PM, 2015.

LAMBERT, Craig. Nuclear weapons or democracy. Harvard Magazine, march-april, 2014. Disponível em: <http://harvardmagazine.com/2014/03/nuclear-weapons-or-democracy>. Acesso em: 9 dez. 2015.

McGREW, A. The globalization debate: putting the advenced capitalist state in its place. Global Society, v. 12, n. 3, 1998.

REIS, Rossana Rocha. O lugar da democracia: a sociedade civil global e a questão da cidadania cosmopolita. Revista de Ciências Sociais da Universidade Estadual Paulista (Unesp), São Paulo, v. 30, p. 15-32, 2006.

RODRIGUES, Saulo Tarso. O direito internacional dos direitos humanos e racionalidade ocidental (razão indolente): a epistemologia e a política ocidental no novo modelo hegemônico de democracia (governação) global. Revista Direito em Debate, Ijuí: Ed. Unijuí, ano XII, n. 21, p. 91-107, jan./jun. 2004.

SCARRY, Elaine. Thermonuclear Monarchy: choosing between democracy and doom. New York: Norton \& Company, 2014.

TOSTES, Ana Paula B; VILLA, Rafael Duarte. Democracia cosmopolita versus política internacional. Revista de Cultura e Política Lua Nova, São Paulo, v. 66, p. 69-107, 2006.

WELLEN, Russ. Nuclear weapons are not only a threat to our survival, but to democracy itself. Foreign policy in focus. Jan. 15th 2013. Disponível em: $<$ http://fpif.org/nuclear_weapons_are_not_only_a_threat_to_our_survival_ but_democracy_itself/>. Acesso em: $10 \mathrm{dez} .2015$. 